\title{
Aneurysm formation after the Norwood procedure: Case report and review of the literature
}

\author{
Jeremy L. Herrmann, MD, Michael J. Lewis, MD, Stephanie Fuller, MD, and Christopher E. Mascio, MD, \\ Philadelphia, $\mathrm{Pa}$
}

The late development of neoaortic arch aneurysms after stage 1 Norwood reconstruction is an uncommon event, ${ }^{1-3}$ and the actual incidence and natural history of this phenomenon remain unclear. We present the oldest such patient to show this life-threatening complication. This case emphasizes the need for long-term surveillance of the neoaorta in this population.

\section{CLINICAL SUMMARY}

A 24-year-old woman who had undergone staged reconstruction consisting of a Norwood procedure with a 4-mm central shunt and ultimately a fenestrated Fontan circulation was seen at an outside hospital for 3 days of intense, persistent left shoulder and chest pain associated with emesis. After myocardial ischemia had been excluded, a transthoracic echocardiogram demonstrated moderate ventricular dysfunction, aortic insufficiency, and aortic enlargement. This prompted a chest computed tomographic scan that revealed an $8.4 \times 10.1-\mathrm{cm}$ aneurysm of the neoaortic arch containing mural thrombus and partially compressing the left main stem bronchus (Figure 1, $A-C$ ). She never had obvious symptoms related to the aneurysm and had been able to carry a pregnancy to term 4 years before her diagnosis.

Once the neoaortic aneurysm was identified, that patient was started on an esmolol hydrochloride (INN esmolol) infusion for blood pressure control and transferred to our institution, where she was taken to the operating room for urgent repair. After induction of anesthesia and establishment of arterial and venous access, the right femoral vessels were cannulated and cardiopulmonary bypass was commenced in anticipation of a difficult mediastinal dissection. Because the aneurysm wall was adherent to the posterior table of the sternum and could not be dissected

\footnotetext{
From the Division of Cardiothoracic Surgery, The Children's Hospital of Philadelphia, Perelman School of Medicine, University of Pennsylvania, Philadelphia, Pa. Disclosures: Authors have nothing to disclose with regard to commercial support.

Received for publication Dec 5, 2013; accepted for publication Dec 18, 2013; available ahead of print Feb 4, 2014

Address for reprints: Jeremy L. Herrmann, MD, Division of Cardiothoracic Surgery, The Children's Hospital of Philadelphia, Perelman School of Medicine, University of Pennsylvania, 34th St and Civic Center Blvd, Suite 12NW10, Philadelphia, PA 19104 (E-mail: jeremy.herrmann@uphs.upenn.edu).

J Thorac Cardiovasc Surg 2014;147:e55-6

0022-5223/ $\$ 36.00$

Copyright (C) 2014 by The American Association for Thoracic Surgery

http://dx.doi.org/10.1016/j.jtcvs.2013.12.056
}

free without disruption of the wall, the patient was cooled to $18^{\circ} \mathrm{C}$ and a resternotomy was performed. The aneurysm was found to involve the entire neoaorta from the sinotubular junction to the descending aortic anastomosis. The uninvolved arch vessels were excised as a single patch. With a 2-graft technique, a 28-mm Hemashield graft (Maquet $\mathrm{GmbH} \&$ Co KG, Rastatt, Germany) was first anastomosed to the distal aorta in end-to-end fashion, followed by anastomosis of the arch vessels with a Carrel patch technique. The proximal graft was clamped, and cardiopulmonary bypass was resumed through the femoral cannulas. The proximal reconstruction was completed with a 30-mm Hemashield graft sewn to the native sinotubular junction, followed by a graft-to-graft anastomosis. Her postoperative course was complicated by seizures, stroke with left-sided upper extremity weakness, and respiratory failure requiring tracheostomy, all of which have resolved or improved. The patient is now ambulating and moving all extremities.

\section{DISCUSSION}

Survival after palliative reconstruction for hypoplastic left heart syndrome continues to improve, as evidenced by the increasing numbers of patients reaching adolescence and young adulthood. ${ }^{4}$ As a result, previously unforeseen complications of Norwood reconstruction are becoming more recognized. Three similar cases of neoaortic aneurysms after Norwood reconstructions have been previously reported, with ages at the time of repair ranging from 4.5 to 12 years and aneurysm size ranging from 5.5 to $17 \mathrm{~cm} .{ }^{1-3}$ Although our 24-year-old female patient is the oldest of these, it is not possible to determine when the aneurysm developed because of her limited follow-up. As far as can be told from this small number of reports, aneurysm development in the reconstructed aorta appears to be an unpredictable phenomenon without a truly known incidence. In these reports, the younger patients who underwent repair at ages 4.5 and 9 years had aneurysms of 5.5 and $7 \mathrm{~cm}$, respectively, and both were symptom free but initially followed up routinely. ${ }^{1,2}$ In contrast, the 2 older patients of 12 and 24 years underwent repair for larger aneurysms (17 and $10 \mathrm{~cm}$, respectively), although the former patient had been followed up for 3 years before repair.,

Neoaortic root dilation has been found to be a common occurrence after staged reconstruction for hypoplastic left 


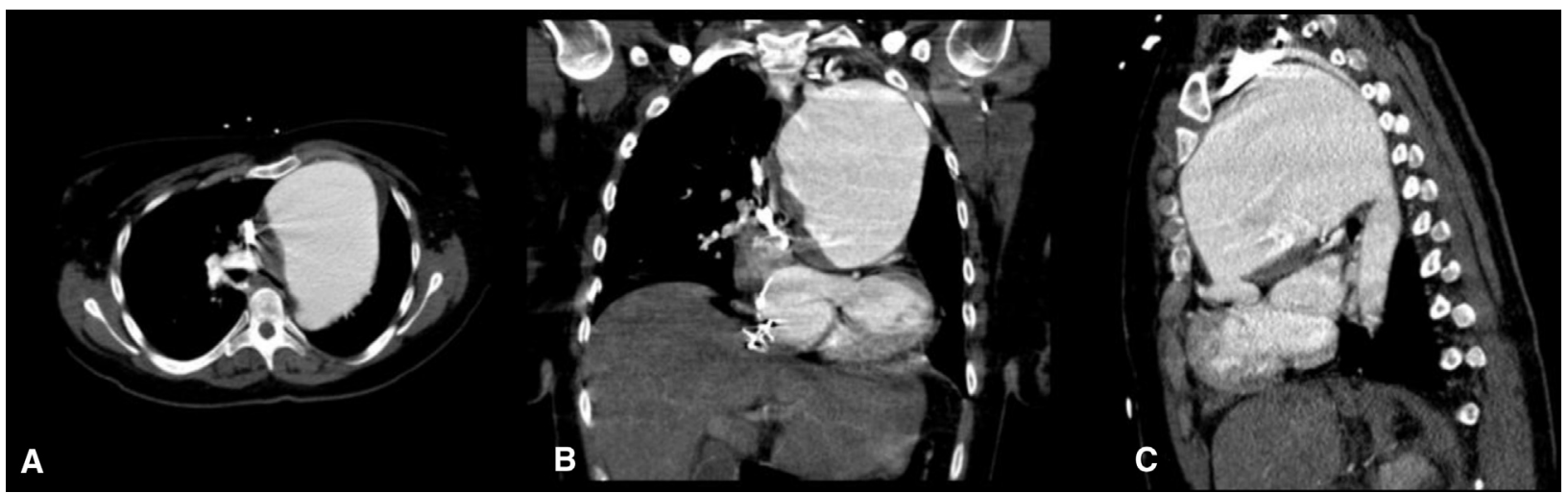

FIGURE 1. Representative computed tomographic images. A and B, Mural thrombus is evident along the wall of the aneurysm. C, Transitions are evident between the sinotubular junction of normal caliber and the descending aorta with interposed aneurysmal neoaorta.

heart syndrome, with $98 \%$ of patients demonstrating a neoaortic dilation with a $z$ score greater than 2 at a median of 9.2 years of follow-up..$^{5}$ The etiology of neoaortic aneurysm formation may involve myxoid degeneration as opposed to atherosclerosis ${ }^{3}$; however, it is unclear whether any contributing factors exist (eg, hypertension, hyperlipidemia, smoking status, pregnancy) and whether medical therapy can mitigate them.

Given that the rate of aneurysmal growth of the neoaorta appears unpredictable and smaller aneurysms may be asymptomatic, it is difficult to determine when a routine surveillance program should be initiated, although it is clear that routine lifetime surveillance is needed for these patients. Routine, long-term surveillance of late survivors of Norwood reconstructions may also shed light on the true incidence and natural history of neoaortic aneurysm formation in this population.

\section{References}

1. Ehsan A, Singh H, Vargas SO, Sachweh J, Jonas RA. Neoaortic aneurysm after stage I Norwood reconstruction. Ann Thorac Surg. 2005;79:e23-5.

2. Shuhaiber JH, Patel V, Husayni T, El-Zein C, Barth MJ, Ilbawi MN. Repair of symptomatic neoaortic aneurysm after third-stage palliation for hypoplastic left heart syndrome. J Thorac Cardiovasc Surg. 2006;131:478-9.

3. Hebson CL, Kanter KR, Maher KO, Slesnick TC. Late development of a gigantic aneurysm of the neoaorta after Norwood palliation. Ann Thorac Surg. 2013;95: 1457.

4. Mahle WT, Spray TL, Wernovsky G, Gaynor JW, Clark BJ 3rd. Survival after reconstructive surgery for hypoplastic left heart syndrome: a 15-year experience from a single institution. Circulation. 2000;102(19 Suppl 3):III136-41.

5. Cohen MS, Marino BS, McElhinney DB, Robbers-Visser D, van der Woerd W, Gaynor JW, et al. Neo-aortic root dilation and valve regurgitation up to 21 years after staged reconstruction for hypoplastic left heart syndrome. J Am Coll Cardiol. $2003 ; 42: 533-40$.

\section{Mapping-guided total excision of the sinoatrial node for inappropriate sinus tachycardia}

Koen Selten, MD, ${ }^{\mathrm{a}}$ Thomas J. Van Brakel, MD, PhD, ${ }^{\mathrm{a}}$ Henry A. Van Swieten, MD, PhD, ${ }^{\mathrm{a}}$ and

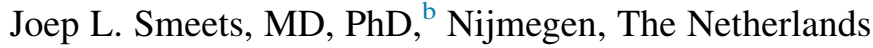

Inappropriate sinus tachycardia (IST) is a syndrome characterized by symptomatic sinus tachycardia at rest and with

From the Department of Cardiothoracic Surgery, ${ }^{\mathrm{a}}$ Radboud University Medical Center, Nijmegen, The Netherlands; and the Department of Cardiology, ${ }^{\mathrm{b}}$ Radboud University Medical Center, Nijmegen, The Netherlands.

Disclosures: Authors have nothing to disclose with regard to commercial support.

Received for publication Dec 7, 2013; accepted for publication Dec 31, 2013; available ahead of print Feb 14, 2014

Address for reprints: Koen Selten, MD, Radboud University Medical Center, Department of Cardiothoracic Surgery, Route 677, Postbus 9101, 6500 HB Nijmegen, The Netherlands (E-mail: koen.selten@radboudumc.nl).

J Thorac Cardiovasc Surg 2014;147:e56-8

$0022-5223 / \$ 36.00$

Copyright (C) 2014 by The American Association for Thoracic Surgery

http://dx.doi.org/10.1016/j.jtcvs.2013.12.055 minimal physical activity. Pharmacologic treatment is often ineffective, and endocardial or epicardial sinus node ablation has proved effective in only a small number of patients with high rates of recurrence. ${ }^{1}$ This report is the first to describe a surgical excision of the total sinoatrial node (SAN) guided by epicardial and endocardial intraoperative mapping as a definitive treatment for a patient with highly symptomatic IST.

\section{CLINICAL SUMMARY}

A 44-year-old male patient with IST and severe symptoms of fatigue, palpitations and dizziness did not have improvement in symptoms and decrease in heart rate 